\title{
INTRODUCTION BY SIR HENRY YELLOWLEES
}

\author{
Chief Medical Officer, Department of Health and Social Security, \\ England and Wales
}

I AM glad of the opportunity to pay tribute to Sir Ludwig Guttmann on his eightieth birthday. In the November 1969 edition of Paraplegia my predecessor, Sir George Godber, described Sir Ludwig's achievement. He placed particular emphasis on Sir Ludwig's insistence on a team approach to the problems of patients with spinal cord lesions. In the decade that has passed since then this approach has become the corner stone of policy in the provision of all forms of health care, not just in the field of rehabilitation.

Sir George wrote that 'no man with Sir Ludwig's drive and purpose could or should be a comfortable colleague for any administrator'. Putting comfort to one side, I would like to consider the contribution Sir Ludwig has made to the development of services for those with traumatic spinal cord lesions, and for the disabled population as a whole. Those he has taught and inspired have gone on to develop his methods throughout the world, as well as in this country.

In the early I960s Sir Ludwig submitted a memorandum to the Ministry of Health pointing out the need for hostels near spinal units for those with tetraplegia and other severely handicapped people with spinal cord lesions, who could not live in their own homes. This emphasis on the social component in treatment and care was part of his insistence on the need for a fully comprehensive service that would allow even the most profoundly disabled patient to return to the community to play a useful and a respected role. The current departmental priority accorded to domiciliary services and the recently initiated Care Attendant Schemes can be seen as a natural extension of this concept.

But services are insufficient on their own, and Sir Ludwig recognised that it would be necessary to change our perception of the severely disabled person if he or she is to be effectively integrated into the community. He recognised the need to overcome much prejudice and dogma, both within the professions and in the larger community, and he pursued his goal with apostolic zeal. The triumphant success of the Stoke Mandeville Games-now the famous International Stoke Mandeville Games for the Paralysed-bear testimony to his achievement, and his own comment that 'in these competitions nobody loses, everybody wins from the mere fact of having competed' is a simple statement of his objectives. Although there are plans to increase the provision for patients with spinal injury in the south of England we may still not have realised all Sir Ludwig's hopes. When I consider this department's policy for Spinal Injury Services I am keenly aware of the enormous debt that these policies owe to this remarkable man, whose vision, tenacity of purpose and achievement is celebrated in this edition of Paraplegia. 